\title{
Enhanced Recovery Protocol After Hand-Assisted Laparoscopic Donor Nephrectomy: A Randomized Clinical Trial
}

\author{
Victor P Alberts ${ }^{1}$, Robert C Minnee ${ }^{1}$, Frederike J Bemelman ${ }^{2}$, Karlijn AMI van der Pant ${ }^{2}$, Markus W \\ Hollmann ${ }^{3}$ and Mirza M Id ${ }^{1^{*}}$ \\ ${ }^{1}$ Department of Surgery, Amsterdam UMC, The Netherlands \\ ${ }^{2}$ Department of Nephrology, Amsterdam UMC, The Netherlands \\ ${ }^{3}$ Department of Anesthesiology, Amsterdam UMC, The Netherlands
}

\begin{abstract}
Introduction: Laparoscopy has improved convalescence after kidney donation. In other surgical fields, enhanced recovery protocol (ERP) has further improved postoperative convalescence. Our aim was to compare ERP with standard care after hand-assisted laparoscopic donor nephrectomy (HALDN).

Methods: In a randomized clinical trial, 52 kidney donors were randomized to ERP ( $n=26)$ or standard care $(n=26)$. Primary outcome was the quality of life one month after surgery (measured by the Short Form-36 (SF-36) questionnaire (dimension "role physical")). Secondary outcomes were postoperative hospital stay, and postoperative complications.

Results: The quality of life ("role physical" dimension score) one month after HALDN surgery was $25 \%$ (SD \pm 6.8 ) in the standard care group versus $37 \%(S D \pm 7.7)$ in the ERP group $(P=0.24)$. There were no significant difference in the other dimension scores of the SF-26 questionnaire between the two groups at one and three months. There are also no significant differences median hospital stay and postoperative complication rate.
\end{abstract}

Conclusions: ERP have no benefit compared with standard perioperative care after HALDN.

Keywords

Enhanced recovery protocol, Hand-assisted laparoscopic donor nephrectomy, Quality of life

\section{Introduction}

Laparoscopic surgery improved postoperative recovery, decreased morbidity and postoperative pain, and shortened hospital stay when compared with open donor nephrectomy, without compromising graft function [1]. Hand-assisted laparoscopic donor nephrectomy (HALDN) and pure laparoscopic donornephrectomy are the two most widely used techniques of donornephrectomy [2]. HALDN results in shorter ischemic times and is the preferred method for donor nephrectomy in our hospital. An enhanced recovery protocol (ERP) is a multimodal approach to patient care using a combination of several peri-operative interventions to enhance recovery after surgery. It has been demonstrated that a ERP protocol for laparoscopic abdominal surgery is safe and effective. ERP combined with laparoscopic technique is associated with a faster postoperative recovery without increasing readmission rate and perioperative mortality [3].

However, kidney donors are no patients but healthy per- sons in outstanding physical condition, and therefore it is not known whether the potential benefits of ERP can be extrapolated to healthy physical active kidney donors. There are limited studies of ERP in laparoscopic donornephrectomy $[4,5]$.

Our aim was to compare ERP care with standard care in HALDN in a randomized clinical trial.

*Corresponding author: Mirza M Idu, Department of Surgery, Amsterdam UMC, location AMC, Meibergdreef 9, 1105 AZ Amsterdam, The Netherlands

Accepted: December 07, 2020

Published online: December 09, 2020

Citation: Alberts VP, Minnee RC, Bemelman FJ, et al. (2020) Enhanced Recovery Protocol After Hand-Assisted Laparoscopic Donor Nephrectomy: A Randomized Clinical Trial. J Transplant Surg 3(1):54-59

Copyright: (C) 2020 Alberts VP, et al. This is an open-access article distributed under the terms of the Creative Commons Attribution License, which permits unrestricted use, distribution, and reproduction in any medium, provided the original author and source are credited. 
Citation: Alberts VP, Minnee RC, Bemelman FJ, et al. (2020) Enhanced Recovery Protocol After Hand-Assisted Laparoscopic Donor Nephrectomy: A Randomized Clinical Trial. J Transplant Surg 3(1):54-59

\section{Patients and Methods}

All adult donors were eligible for inclusion in this randomized clinical trial. Exclusion criteria were expected problems with the placement of a thoracic epidural catheter, the inability to give informed consent, use of psychopharmacological medication, chronic use of analgesics, and use of non-steroid anti-inflammatory drugs (NSAIDs) within five days before surgery. The Charlson Comorbidity Index was calculated for each donor to evaluate comorbidities in the two groups [6]. Donors were discharged when they complied with the following discharge criteria: 1) Adequate pain control with oral analgesics; 2)Absence of nausea; 3) Toleration of solid food; 4) Passage of flatus or stools; 5) Full mobilization and 6) Acceptance of discharge by the donor. The operation in both groups was performed under general anesthesia with propofol or volatile anesthetics, fentanyl or sufentanil and a muscle relaxant. Dexamethason $8 \mathrm{mg}$, droperidol $0.625 \mathrm{mg}$ and ondansetron as needed were used as antiemetics.

The hand-assisted laparoscopic donornephrectomy technique and the surgeon was identical in both study groups. Written informed consent was obtained from all subjects. The study was conducted in accordance with the principles of the declaration of Helsinki and according to the CONSORT statement. The independent medical ethics review board approved the study protocol. The study was registered under NTR2080 (www.trialregister.nl).

\section{Enhanced recovery protocol (ERP)}

ERP donors were offered caloric preloading (four portions of $200 \mathrm{ml}$ carbohydrate-loaded ( $\mathrm{CHL}$ ) drinks on the eve of the operation and two portions two hours before surgery). ERP donors were not allowed to take preoperative sedatives. In the operation room a thoracic epidural catheter was inserted with $8-10 \mathrm{ml}$ bupivacaine $0.25 \%$ and either $20 \mu \mathrm{g}$ sufentanil or $150 \mu \mathrm{g}$ fentanyl. Postoperatively, a continuous infusion of bupivacaine $0.125 \%$ and fentanyl $2.5-5.0 \mu \mathrm{g} / \mathrm{ml}$ 6-12 $\mathrm{ml} /$ hour was administered combined with $1000 \mathrm{mg}$ paracetamol four times a day. At postoperative day (POD) 2 the epidural catheter was removed and $50 \mathrm{mg}$ tramadol was given three times a day in combination with paracetamol until no longer needed. When placement of the epidural catheter failed patient controlled analgesia (PCA) using morphine was given combined with low dose of ketamine until POD 2. The urine catheter was removed at POD 1. A minimum of two hours chair mobilization is required on POD 0 and a minimum of six hours on the following days. Full oral intake had to be $800-1000 \mathrm{ml}$ on POD 0 including two portions of $\mathrm{CHL}$ drinks, two liters of oral intake on POD 1 including three portions of $\mathrm{CHL}$ drinks and a normal diet on POD 2 including two grams of magnesiumoxide. Donors were discharged on POD 3 if they met the discharge criteria.

\section{Standard care protocol}

Standard care donors did not receive caloric preloading. Preoperative sedatives were given the eve of donor nephrectomy. Postoperative analgesia was given by PCA using morphine which was continued until POD 2 or until the anesthesiologist deemed unnecessary. When the PCA was stopped $50 \mathrm{mg}$ tramadol was given three times a day in combination with paracetamol until it was no longer needed. The urine catheter was removed at POD 1 . On POD 0 the donors received a clear liquid diet and mobilized at will. From POD 1 onwards donors received any preferred diet and mobilized at will. Donors were discharged when they met the discharge criteria.

\section{Primary and secondary outcomes}

The quality of life measured with the Short Form-36 (SF36) questionnaire was used as primary outcome [7]. The SF36 constitute eight dimension scores. The dimension scores are physical functioning, role physical (role limitations due to physical health problems), bodily pain, general health perception, vitality, social functioning, role emotional (role limitations due to emotional problems), and mental health. In our earlier studies we used the SF-36 questionnaire to study quality of life aspects after the operation, and we demonstrated that the dimension score "physical functioning" was the lowest at one week after the operation [8]. This dimension score is a numeric value of the physical functioning capacity at the moment the questionnaire is filled out. The primary outcome as defined in our protocol was the dimension score "physical functioning" at 1 week after the operation.

However, due to unfortunate error in our patient mailing list to the donors the first SF questionnaire was filled in 4 weeks after the operation. So we were not able to calculate any SF-36 scores at 1 week after the operation. However, in our earlier study we also demonstrated that the operation had significant effect on the dimension score "role physical". This dimension "role physical" evaluates the physical health problems within the whole first 4 weeks after the operation. Therefore we used this as our "alternative" primary outcome.

Secondary outcomes were postopertaive pain, postoperative hospital stay, and postoperative complications (Clavien-Dindo classification Grade I or higher). The Multidimensional Fatigue Inventory-20 (MFI-20) was used to evaluate fatigue. Donors were also questioned on the amount of recovered activity at home and at work. The questionnaires were scored preoperatively and postoperatively after one and three months. The post-operative pain was measured with a 0 to 10 scale (VAS) in rest and exertion was analyzed on postoperatieve day 1 to 3 . Follow-up was at least three months.

\section{Randomization}

Randomization was done by means of an Internet block randomization module after informed consent was obtained at the outpatient department. Blinding was not performed, but there were strict written protocols on the ward for both groups and both nursing and medical staff had been extensively trained to execute both treatment protocols.

\section{Statistical analysis and sample size calculation}

The initial primary endpoint was the dimension "physical functioning" measured by the SF-36 questionnaire one week after surgery. A 20-point difference was considered clinically significant. The 20-point cut-off is generally used for clinical significance. Considering a standard deviation (SD) of 25 
Citation: Alberts VP, Minnee RC, Bemelman FJ, et al. (2020) Enhanced Recovery Protocol After Hand-Assisted Laparoscopic Donor Nephrectomy: A Randomized Clinical Trial. J Transplant Surg 3(1):54-59

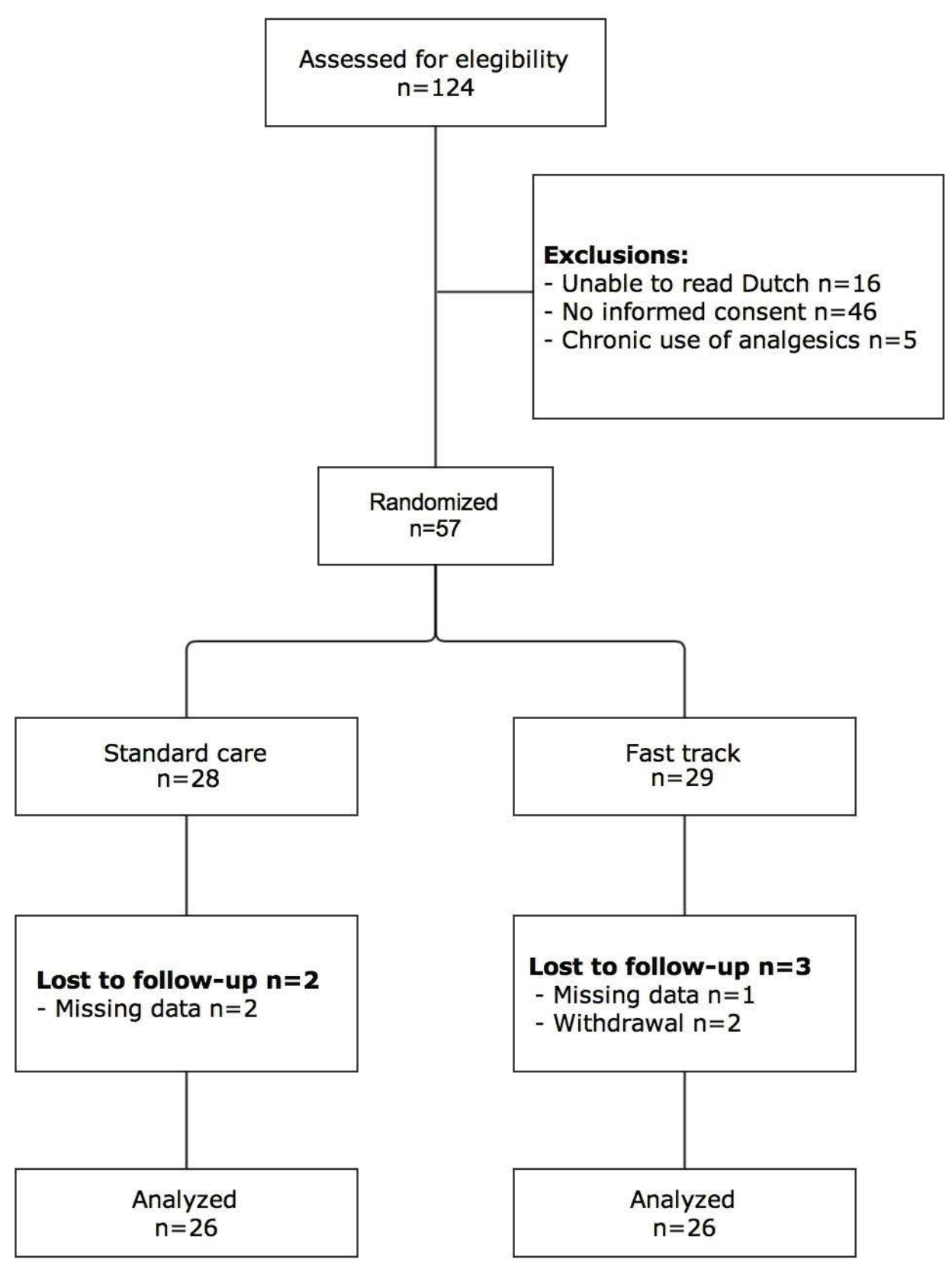

Figure 1: Study flowchart. Fast track $=$ ERP.

it was calculated that with a power of $80 \%$ and a two-sided alpha of $0.05,26$ donors per group were needed. With hospital stay as secondary outcome 21 donors per group were needed to detect a one-day reduction of hospital stay. Treatment groups were compared with the $\chi^{2}$ test for dichotomous outcomes and the Mann-Whitney $U$ test for continuous variables. A two-sided $P$ value $<0.05$ was considered statistically significant. Statistical analyses were performed using SPSS for Windows version 16 (SPSS Inc. Chicago, IL).

\section{Results}

In 35 months 124 adult donors were eligible for inclusion and eventually a total of 52 donors (26 per group) were included in the analysis (Figure 1). There were no cross-overs between the groups. Baseline characteristics (including comorbidities) did not differ significantly between both groups
(Table 1). One ERP donor postoperatively received PCA after failed placement of a thoracic epidural catheter. The adherence of the ERP donors to the different items of the ERP protocol are listed in Table 2.

The "role physical" dimension score one month after HALDN surgery (the "alternative" primary outcome) was $25 \%$ $(S D \pm 6.8)$ in the standard care group versus $37 \%(S D \pm 7.7)$ in the ERP group $(P=0.24)$. Our "initial" primary outcome the "physical functioning" dimension score not at 1 week but at 1 month after HALDN surgery was $73 \%$ (SD \pm 2.6 ) in the standard care group versus $75 \%$ (SD \pm 3.0 ) in the ERP group $(P=$ $0.43)$. There were also no significant difference in the other dimension scores of the SF-26 questionnaire between the two groups at one and three months.

The postoperative outcomes are presented in Table 3. 
Citation: Alberts VP, Minnee RC, Bemelman FJ, et al. (2020) Enhanced Recovery Protocol After Hand-Assisted Laparoscopic Donor Nephrectomy: A Randomized Clinical Trial. J Transplant Surg 3(1):54-59

Table 1: Baseline characteristics of donors and surgical aspects.

\begin{tabular}{|l|l|l|l|}
\hline & Standard care $(\mathbf{n}=\mathbf{2 6})$ & ERP $(\mathbf{n}=\mathbf{2 6})$ & P value \\
\hline Age in years, mean $( \pm$ SD) & $54( \pm 11)$ & $55( \pm 10)$ & 0.73 \\
\hline Female sex & 17 & 15 & 0.57 \\
\hline Body mass index in $\mathrm{kg} / \mathrm{m}^{2}$, mean $( \pm \mathrm{SD})$ & $26( \pm 3)$ & $26( \pm 3)$ & 0.91 \\
\hline Smoking & 3 & 16 & 0.44 \\
\hline Family related donation & 10 & 15 & 0.10 \\
\hline Charlson Comorbidity Index score & & 9 & 0.39 \\
\hline $0-1$ & 18 & 2 & 0.21 \\
\hline 2 & 5 & 16 & 0.64 \\
\hline 3 & 3 & $143(128-152)$ & 0.23 \\
\hline Left sided nephrectomy & 20 & $30(28-50)$ & 0.63 \\
\hline Operating time in minutes, median (IQR) & $146(134-168)$ & 0.43 \\
\hline Blood loss in ml, median (IQR) & $30(20-50)$ & \\
\hline
\end{tabular}

$\mathrm{SD}=$ standard deviation, $\mathrm{IQR}=$ interquartile rang

Table 2: Adherence to ERP protocol.

\begin{tabular}{|c|c|c|c|}
\hline & \multirow{2}{*}{$\begin{array}{l}\text { Standard care } \\
(n=26)\end{array}$} & \multirow{2}{*}{\begin{tabular}{|l} 
ERP \\
$(n=26)$
\end{tabular}} & \multirow[t]{2}{*}{$P$ value } \\
\hline & & & \\
\hline \multicolumn{4}{|l|}{ CHL intake } \\
\hline $800 \mathrm{ml}$ on eve before surgery & 0 & 21 & \\
\hline $400 \mathrm{ml} 2$ hours before surgery & 0 & 25 & \\
\hline $400 \mathrm{ml}$ on POD 1 & 0 & 22 & \\
\hline No preoperative sedatives & 5 & 22 & 0.045 \\
\hline Thoracic epidural analgesia & 0 & 25 & \\
\hline Patient controlled analgesia & 24 & 1 & \\
\hline \multicolumn{4}{|l|}{ Postoperative mobilization } \\
\hline At least 2 hours on POD 0 & 4 & 14 & 0.003 \\
\hline At least 6 hours on POD 1 & 8 & 21 & $<0.001$ \\
\hline At least 6 hours on POD 2 & 15 & 23 & $<0.001$ \\
\hline At least 6 hours on POD 3 & 19 & 24 & 0.23 \\
\hline Urine catheter removed on POD 1 & 15 & 17 & 0.54 \\
\hline Normal diet on POD 2 & 19 & 26 & 0.06 \\
\hline
\end{tabular}

$\mathrm{CHL}=$ Carbohydrate loaded drink; POD = Postoperative day

Table 3: Postoperative outcomes.

\begin{tabular}{|l|l|l|l|}
\hline & Standard care $\mathbf{n}=\mathbf{2 6})$ & ERP $(\mathbf{n}=\mathbf{2 6})$ & P value \\
\hline $\begin{array}{l}\text { Postoperative complications } \\
\text { (Grade I Clavien-Dindo classification) }\end{array}$ & 1 & 1 & \\
\hline Hospital stay in days, median (IQR) & $4(3-4)$ & $3(3-4)$ & 0.63 \\
\hline Able to work after 1 month & 5 & 4 & 0.82 \\
\hline Able to work after 3 months & 14 & 18 & 0.11 \\
\hline Perception of recovery score (0-100) & & $71 \pm 21$ & 0.11 \\
\hline After 1 month (mean \pm SD) & $64 \pm 19$ & $89 \pm 14$ & 0.28 \\
\hline After 3 months (mean \pm SD) & $84 \pm 18$ & \\
\hline
\end{tabular}

$\mathrm{POD}=$ Postoperative day; IQR = Inter quartile range; $\mathrm{SD}=$ Standard deviation 

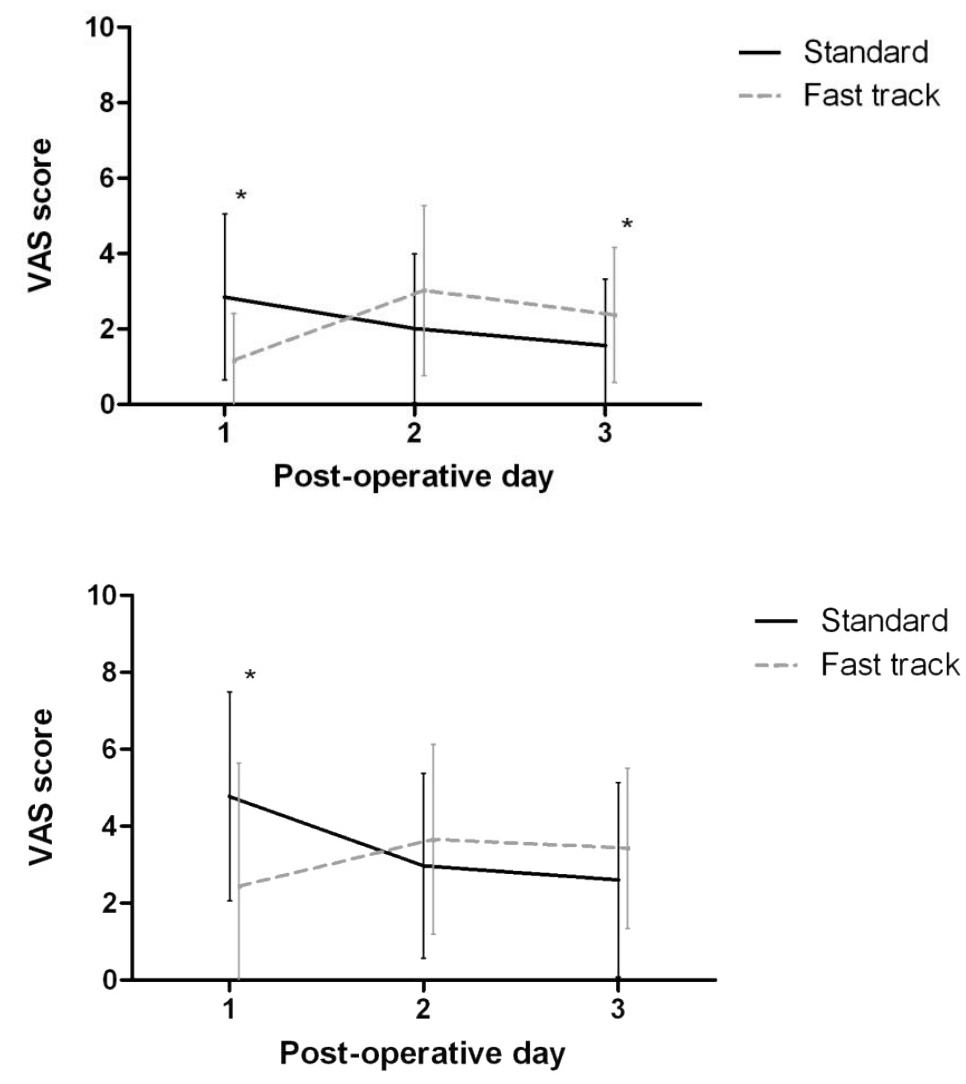

Figure 2: Postoperative pain in rest (upper) and dynamic pain (lower) as measured by the VAS for pain (mean $\pm 2 x$ SEM) on postoperative day 1,2,3. Asterisks indicate a significant difference between both study groups. Fast track $=\mathrm{ERP}$.

There no readmission in both groups. One donor in the standard care group developed an ileus that was conservatively treated, and one donor in the ERP group developed postoperative migraine. Both were grade I complications in the Clavien-Dindo classification. There were no grade II or higher complications. There are no significant differences in the MFI20 survey, median hospital stay, working ability, recovery perception and postoperative complication rate between the two groups at the different time points.

The pain VAS of both groups of the first 3 postoperative days are shown in Figure 2. Postoperative pain scores were significantly lower in the ERP group on POD 1 in rest and dynamic pain (respectively, $P=0.005$ and $P=0.001$ ). However, on POD 3 ERP donors had significantly more pain in rest $(P=$ 0.032).

\section{Discussion}

Unfortunately our first post-operative quality of life data (SF-36) are after 1 month after the operation and therefore we could not analyze our initial primary endpoint which was the dimension score physical functioning 1 week after the operation. At one and three months after the operation we could not find any significant effect of the ERP over standard care after kidney donation. In addition our randomized controlled trial did not show a significant difference in hospital stay, working ability and perception of recovery at 1 and 3 months after the operation. Besides removal of the urine catheter at POD 1 there was a good adherence to the different items of the ERP protocol in our study.

In theory there could be a significant effect of ERP in HALDN compared with standard care but this eventual difference is gone after 1 month.

Many kidney donors are very well informed about the complete procedure and what the expectations are, even before they see a doctor for the first time. They know what can be expected after the operation and that can potentially influence the recovery as well. The good physical and psychological status of kidney donors, as demonstrated in our Charlson Comorbidity Index results, might be the reason why the ERP did not show improved convalescence or shorter hospital stay after HALDN in our study. Our results are comparable with those of the recent study of Ricotta, et al. [5].

The use of epidural anesthesia in our study significantly reduced pain on the first postoperative day. The epidural anesthesia was stopped on postoperative day 2. Hereafter, ERP donors reported significantly more pain than standard care donors on postoperative 3 . It is hypothesized that this increased experience of pain was due to an increased perception of pain after cessation of the epidural catheter. However, pain scores in both groups were relatively low. Therefore, it is questionable if these results have clinical significance. The complication rate was comparable between both groups. 
In the recent study of Brown et al. there was also no difference in pain scores and postoperative complications after a ERP in laparoscopic donornephrectomy [4].

Post-operative fatigue lasting for weeks is a well known side effect after kidney donation. To investigate the potential effect of a ERP on the post-operative fatigue we included the MFI-20 questionaire. However, we could not detect any significant difference between both study groups.

Other limitations of this study were the lack of blinding. The differences in protocol elements could not be blinded since the same medical and nursing staff treated both donor groups. Strict adherence to the written protocol was used to limit the lack of blinding effect as much as possible. The small sample size could be the reason for non-significant results. However, the number of included donors was the minimum according to the sample size calculations. Increasing the number of patients could probably detect smaller differences but those differences would not be clinical significant.

In conclusion, a ERP program did not show a significantly enhanced recovery at 1 and 3 months after HALDN when compared with standard perioperative care.

\section{References}

1. Wilson CH, Sanni A, Rix DA, et al. (2011) Laparoscopic versus open nephrectomy for live kidney donors. Cochrane Database Syst Rev.
2. Broe MP, Galvin R, Keenan LG, et al. (2018) Laparoscopic and hand-assisted laparoscopic donor nephrectomy: A systematic review and meta-analysis. Arab J Urol 16: 322-334.

3. Zhengyan Li, Qingchuan Zhao, Bin Bai, et al. (2018) Enhanced Recovery After Surgery Programs for Laparoscopic Abdominal Surgery: A Systematic Review and Meta-analysis. World J Surg 42: 3463-3473.

4. Brown T, Magill F, Beckett N, et al. (2020) Introduction of an enhanced recovery protocol into a laparoscopic living donor nephrectomy programme. Ann R Coll Surg Engl 102: 204-208.

5. Ricotta C, Cintorino D, Pagano D, et al. (2019) Enhanced Recovery after Implementation of Surgery Protocol in Living Kidney Donors: The ISMETT Experience. Transplant Proc 51: 2910-2913.

6. Charlson M, Szatrowski TP, Peterson J, et al. (1994) Validation of a combined comorbidity index. J Clin Epidemiol 47: 1245-1251.

7. Aaronson NK, Muller M, Cohen PD, et al. (1998) Translation, validation, and norming of the Dutch language version of the SF-36 Health Survey in community and chronic disease populations. J Clin Epidemiol 51: 1055-1068.

8. Minnee RC, Bemelman WA, Polle SW, et al. (2008) Older living kidney donors: surgical outcome and quality of life. Transplantation 86: 251-256.

DOI: $10.36959 / 338 / 333$

Copyright: (c) 2020 Alberts VP, et al. This is an open-access article distributed under the terms of the Creative Commons Attribution License, which permits unrestricted use, distribution, and reproduction in any medium, provided the original author and source are credited. 